\title{
P 007 HELPING PATIENTS TO DIE AT HOME: CARERS' VIEWS ON HOME CARE WITH THE MIDHURST MACMILLAN SPECIALIST PALLIATIVE CARE SERVICE
}

Philippa Hughes, Michelle Winslow, Christine Ingleton, Bill Noble. University of Sheffield, Sheffield, UK

\subsection{6/bmjspcare-2014-000654.47}

Background The Midhurst Macmillan Specialist Palliative Care Service (MMSPCS) is a UK, medical consultant-led, multidisciplinary team providing care in the home, community hospitals and care homes. Care includes specialist interventions. Case data review shows that over two thirds of patients referred to the service die at home.

Aim and Methods As part of a multi-method evaluation study we conducted a survey of bereaved carers of patients referred to the MMSPCS, using the Views of Informal Carers- Evaluation of Services (VOICES) self-complete postal questionnaire.

Results Response rate was 40.5\% (102/252). 83\% of respondents reported services at home to be excellent or good, and $78 \%$ reported receiving as much support as they wanted. $74 \%$ reported receiving care from two or more nursing services. $43 \%$ of respondents had given up or reduced their work to look after their relative. Confidence of informal carers in looking after their relative varied, with only $32 \%$ reporting feeling very confident. $49 \%$ reported the caring experience as rewarding, $7 \%$ as a burden, and $28 \%$ equally balanced (14\% other replies/missing). There were 20 comments from those who found it rewarding: 
including on the value of maintaining family life, deepening relationships, enabling a wished for death at home, and on the tiring and difficult nature of providing care. There were five comments from those who found it a burden; including feeling they had not provided good enough care, and feeling frightened or sad. There were 25 comments from others, including feeling glad to provide care while acknowledging the sadness and anxiety of this; rejecting the terms 'burden' and 'reward'; and the challenges and responsibility involved.

Conclusion Good services are key to care at home, but also key are informal carers at home. Carers report difficulties and challenges alongside positive experiences at home, reflecting the complexity in this area. 